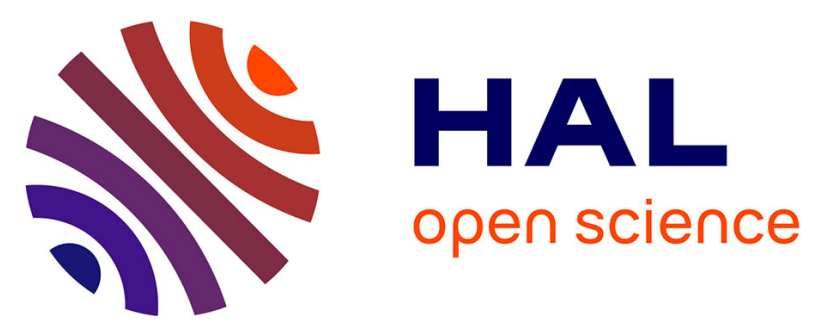

\title{
Basic Digital Education in Austria - One Step Further
}

\author{
Peter Micheuz, Stefan Pasterk, Andreas Bollin
}

\section{To cite this version:}

Peter Micheuz, Stefan Pasterk, Andreas Bollin. Basic Digital Education in Austria - One Step Further. 11th IFIP World Conference on Computers in Education (WCCE), Jul 2017, Dublin, Ireland. pp.432442, 10.1007/978-3-319-74310-3_44. hal-01762858

\section{HAL Id: hal-01762858 https://hal.inria.fr/hal-01762858}

Submitted on 10 Apr 2018

HAL is a multi-disciplinary open access archive for the deposit and dissemination of scientific research documents, whether they are published or not. The documents may come from teaching and research institutions in France or abroad, or from public or private research centers.
L'archive ouverte pluridisciplinaire HAL, est destinée au dépôt et à la diffusion de documents scientifiques de niveau recherche, publiés ou non, émanant des établissements d'enseignement et de recherche français ou étrangers, des laboratoires publics ou privés.

\section{(c)(1)}

Distributed under a Creative Commons Attribution| 4.0 International License 


\title{
Basic Digital Education in Austria - One Step Further
}

\author{
Peter Micheuz, Stefan Pasterk, Andreas Bollin \\ Institute of Informatics Didactics, Alpen-Adria-University, Klagenfurt, Austria \\ peter .micheuz; stefan . pasterk; andreas .bollin@aau.at
}

\begin{abstract}
Based on a nearly thirty years long history to implement digital education in Austrian primary and lower secondary schools, this paper deals with the current development and strategies to encounter this challenge. After a literature review across national borders and some findings on different approaches in two different countries, a compressed historical view and exemplary empirical results from onlinesurveys describe the current Austrian situation. The paper closes with the outlines of the new curriculum "Basic Digital Education” and some remarks about it.
\end{abstract}

Keywords. Curriculum, Informatics, Digital Literacy, Media Literacy

\section{Introduction}

Up to now, digital education at primary and lower secondary level (grades 1-8) of Austrian schools is still to be seen as a patchwork lagging behind the requirements of a digital society in which all pupils should have equal access to "IT". About thirty years ago computers entered all secondary schools, with Informatics as an obligatory subject for upper secondary level. From the beginning on it was up to schools to offer ICT and Informatics education autonomously and non-obligatorily at lower grades.

In 2005, the situation was described like this [15].

- The digital gap between pupils at the end of lower secondary schools is unacceptably wide.

- Due to autonomy and inhomogeneous competences of teachers, the status of ICT/informatics differs extremely from school to school,

- Simplification and clarification of terminology in the context of ICT and Informatics are a matter of concern.

- There is a need for a reasonable framework which ensures also a certain level of digital literacy.

- Standardizing measures should be taken, so that pupils leaving lower secondary schools should have acquired a reasonable and clearly defined standard of digital and Informatics competence.

While the first two statements still hold true, resolving the other three requirements moves closer through promising top down actions by the Austrian Ministry of Education on a solid legal basis in form of a national curriculum. This year (2017) has the potential to go down in history as the year which marks the transition to accountability in form of a national curriculum for a new subject "Basic Digital Education”, similar to the introduction of the new introduced subject Informatics in 
1985 for all pupils in grade 9. Many single initiatives at local school level and grass root movements are about to get the long-awaited top-down support.

Currently, a draft curriculum for grades 5-8, building upon preliminary (inter)national work, has been devised. It will be piloted in 2017/18 within a recently constituted big Austrian network and a ministerial project of digitally advanced schools, called "eEducation" [16]. Provided that after a national election in autumn 2017the political situation stays stable, the curriculum will be decreed by the Austrian Ministry of Education for all schools.

Every major project and political measure builds vertically on nationally and regionally grown structures and horizontally on comparable developments in other countries. After a short survey on international initiatives and a compressed look back into the short history of computers in Austrian schools, this paper closes with the presentation of the outlines of new curriculum and its constraints, followed by hinting at some challenges which lie ahead.

\section{Looking Beyond National Borders}

When looking beyond national borders, a lot of different models for education in digital and information technologies in elementary and secondary schools can be found. Following a report from the European Schoolnet [7] in 2015, several of the 21 participating European countries introduce digital technology related content in their national curriculum. In most cases, this content is part of curricula or educational standards for Computer Science, Computing or Informatics [7]. The Schoolnet report shows that the priorities for ICT skills concentrate on 'Digital Competence' for 19 countries. Only 10 of the participating countries focus on 'Computing and Coding skills' [7]. So, for most participating countries Digital Competence is a main goal to reach and can be understood as the 'confident, critical and creative use of ICT to achieve goals related to work, employability, learning, leisure, inclusion and/or participation in society' [9]. This definition was used in the DIGCOMP project to identify descriptors of digital competence in Europe [9], resulting in a framework that provides following five areas of digital competence:

1. Information: organize and analyze digital information

2. Communication: communicate and collaborate in digital environments

3. Content-Creation: create and edit new content including programs

4. Safety: safe use and protection of data

5. Problem-solving: identify digital needs and resources, make informed decisions on most appropriate digital tools according to the purpose or need, solve conceptual problems through digital means, creatively use technologies, solve technical problems, update own and other's competence [9]

After an update of this framework to DIGCOMP 2.0 in 2016, the first three areas were changed into Information and data literacy (instead of Information), Communication and collaboration (instead of Communication), and Digital content creation (instead of Content creation) [10].

Besides this European framework, several countries introduced their own curriculum for digital education in primary and secondary schools, like, for example, 
England with the subject 'Computing' in 2014 [2]. Following Berry [5], the curriculum of the subject "Computing" [2] can be divided into the three aspects: Computer Science (CS), Information Technology (IT), and Digital Literacy (DL). Where the strand CS concentrates on 'fundamental principles and concepts of computer science' and first steps in programming, the strands IT and DL focus on the use (IT) and the 'responsible, competent, confident and creative' handling (DL) of information technology [5].

In Switzerland, the curriculum for primary and lower secondary education (called 'Lehrplan 21') was presented in 2014 and accepted by 21 of the 26 cantons. Each canton was able to adapt the original version of this curriculum [3]. It contains the subject 'Medien und Informatik (Media and informatics)' which starts in the first year of primary school. Where the media part focuses on the understanding and responsible use of media, in informatics the basic concepts of computer science and problem solving are included. Furthermore, the application competence should be fostered in the other subjects [3].

In a new curriculum for Informatics in Poland [11], presented in 2015, the subject is obligatory for primary and secondary education. The curriculum is a modification and extension of the former curriculum which also provided informatics on each education level. It includes unified aims defining following five knowledge areas, which are the same for each school level: Understanding and analysis of problems; Programing and problem solving by using computers and other digital devices; Using computers, digital devices, and computer networks; Developing social competences; and Observing law and security principles and regulations [11].

Looking at the USA, each state can have an own curriculum for computer science and ICT. As a proposal for teachers and curriculum developers, the CSTA (Computer Science Teachers Association) presented a model curriculum for K-12 computer science in 2003 [4], containing the use of technologies for learning, as well as topics like binary numbers, algorithms, and fundamental logic. In a next step the oftenreferenced K-12 Computer Science Standards of the CSTA [1] were developed. They are categorized into the five strands Collaboration; Computational Thinking; Computing Practice and Programming; Computers and Communications Devices; and Community, Global, and Ethical Impacts, which are very extensive and consider the use and the technical background of digital devices as well as programming skills. In 2016, these CS standards were revised, based on the in 2016 published K-12 Computer Science Framework [12,] and an interim version of new K-12 Computer Science Standards was published by the CSTA [8]. The framework includes seven core practices including computational thinking, which 'describe the behaviors and ways of thinking that computationally literate students use to fully engage in today's data-rich and interconnected world' [12], and five core concepts, which 'represent major content areas in the field of computer science' [12]. The core practices are

1. Fostering and inclusive computing culture

2. Collaborating around computing

3. Recognizing and defining computational problems

4. Developing and using abstractions

5. Creating computational artifacts

6. Testing and refining computational artifacts

7. Communicating about computing 
In addition, the core concepts of the framework are Computing Systems; Networks and the Internet; Data and Analysis; Algorithms and Programming; and Impacts of Computing [12].

The Australian curriculum [6], introduced in 2015, includes two subjects Design and Technologies and Digital Technologies from primary to secondary education. Design and Technologies focuses on the impact of technologies on society and related design topics, whereas Digital Technologies covers the background and the use of information technology. Both subjects are divided into the two blocks Knowledge and understanding and Processes and production skills. In Digital Technologies the content areas Digital systems and Representation of data are part of the Knowledge and understanding block. The Processes and production skills block includes Collecting, managing and analyzing data and Creating digital solutions by investigating and defining, generating and designing, producing and implementing, evaluating, and collaborating and managing [6].

It seems that the structure and content of the curricula are well defined, but there is still room for improvement. During an ongoing project to analyze the quality of curricula [13] together with seven experts with didactical background, one is able to identify weakness in both, structure and content. Fig. 1 visualizes the differences of the curricula from Switzerland (a.) and Australia (b.) by mapping their core competences and their relations for the first six school levels to a graph database and expressing the priorities for digital literacy or computer science topics. As the dark nodes represent skills concerning digital literacy, and the light nodes correspond to computer science skills, it can be seen, that the curriculum in Switzerland (a.) focuses on digital literacy. Following the majority of the experts, eleven of the overall 44 skills can be matched to computer science.

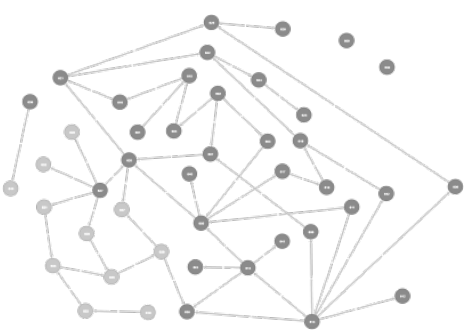

(а.)

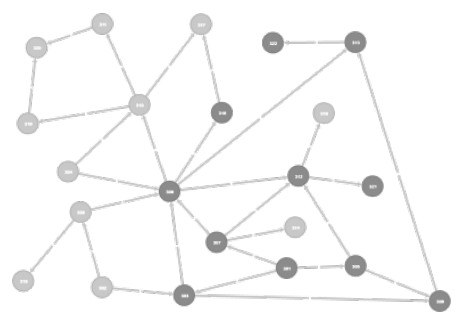

(b.)

Fig. 1. Curriculum from Switzerland (a.) and Australia (b.) represented as a graph

For comparison, the results from the Australian curriculum, as shown in Fig. 1 (b.), look a bit different. From overall 22 skills also eleven were matched to 'computer science'. This indicates a better balanced distribution of the topics, but with the provision that the decisions from the experts were not that clear, with one third of the matches being very close. 


\section{A Very Short History of Digital Education in Austria}

This recent project and legal measure to implement a new curriculum for Basic Digital Education has a well-documented prehistory. After the very roots and single initiatives from 1970 on, the nationwide introduction of computers in schools at lower secondary level started from the period 1985-1990 on. This time can be denoted as an experimental one, with many computer pioneers among (programming) teachers. The last decade in the $20^{\text {th }}$ century was characterized by networked computers, the beginning of the GUI era (1990-1995) followed by autonomy, the kickoff of the internet era (1995-2000), and the rise of application software at the expense of programming in Informatics lessons. During the first decade from 2000 to 2010, the term eLearning, accompanied practically by many (pilot) projects and (inter)national networks, emerged. At this time, educational standards have been introduced.

Due to the lack of a national curricula at primary and lower secondary level, ICT and Informatics developed very inhomogeneously throughout the country. This decline of digital education at this time was reinforced by a nationwide reduction of lessons in 2003 which made it almost impossible to implement ICT/Informatics lessons at the expense of other subjects.

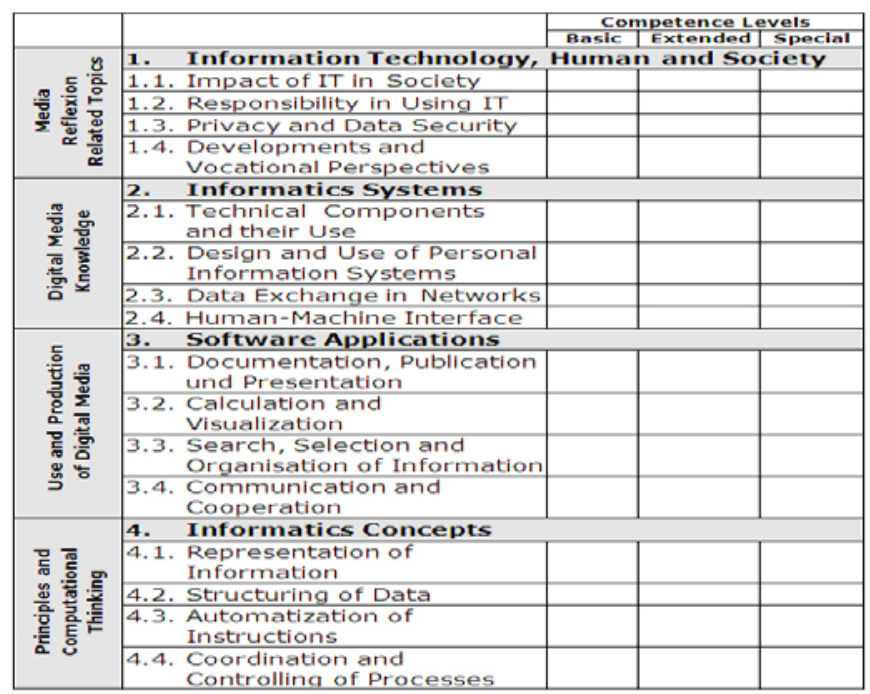

Table 1. Competence Matrix for Basic Informatics Education for Austria’s primary and lower secondary level (K4/K8, 7-14 years)

A new era began with the development of the competence model 2011 [14] as depicted in Table 1. For the first time a holistic view on basic informatics education in Austria has been devised, leading to engagements of task forces which produced teaching and learning material as open educational resources [18]. The projects Digikomp4 for primary and Digikomp8 for lower secondary education can be seen as the building block of the new curriculum for Basic Digital Education (Digitale Grundbildung). The problem with every conceptual framework and even the offer of 
corresponding free teaching materials is its non-legally binding nature. Having never been evaluated nationally, the initiative Digikomp8 could not fulfill the requirements of executed educational standards and an attained curriculum for the majority of pupils.

Digikomp4 for primary level (grades 1-4), building on the same reference model as Digikomp8 (with 71 competences), but with less and age-appropriate 49 competences, has been published a little bit later [19]. Due to the special situation in primary schools (lack of particularly educated teachers and no legal anchoring in the curriculum) it has reached only a little selection of primary schools and pupils.

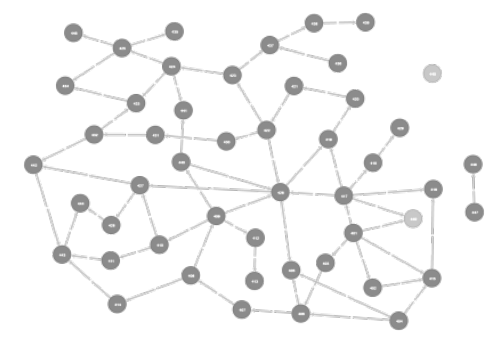

Fig. 2. Digikomp4 competency model represented as a graph

Fig. 2. represents the competences and their relations in a graph, as it was done in the previous section with the curricula from Switzerland and Australia (Fig. 1). There was a $90 \%$ agreement from the experts that only two competences matched with computer science. Contrary to the proportion of computer science in the curricula of Australia and the geographically neighboring Switzerland, the Austrian competences at primary level are application oriented.

\section{Some Findings from a Nationwide Empirical Research}

Two nationwide online-surveys in form of online-questionnaires among teachers and teacher trainers, involved in digital education, have been conducted with an interval of one year at the end of 2015 and 2016. They mainly consisted of rating questions asking the survey respondents for their personal opinions to compare different items using a common scale. The response to the first survey 2015 was very good (424), whereas the response to the second one at the end of 2016 (127) can be regarded as satisfying. One reason for this significant decline in the response number is due to the fact that it aimed at expert teachers with a broader national overview and insight regarding the national digital sociotope.

The very first request in the survey 2015 was "Please rate the overall situation of Digital Education in Austria on a rating scale of 1-10, where 1 is 'very good' and 10 is 'very bad'). 


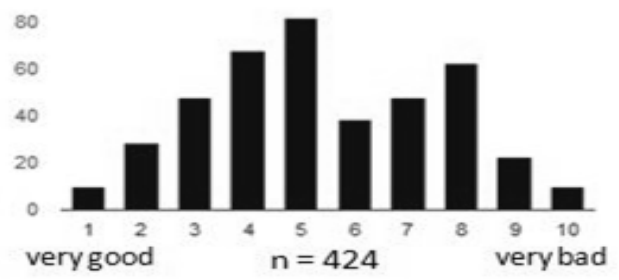

Fig. 3. Rating of the overall situation of digital education in Austria 2015

The diagram in Fig. 3, expressing the personal attitudes towards the comprehensive term "Digital Education/Digitale Bildung” which is comparatively new in German speaking countries, is expectedly balanced and not too negative, but with a striking local maximum at the scale value 8 .

Table 2. Cumulated exemplary results from the survey 2015

\begin{tabular}{|c|c|c|c|c|c|c|}
\hline Primary Education & yes & rather yes & rather no & no & & n.a. \\
\hline Informatics content should be taught mandatorily. & 102 & 106 & 69 & 39 & I & 25 \\
\hline Application competences should be mandatory. & 126 & 107 & 59 & 31 & I & 21 \\
\hline Lower Secondary Education & yes & rather yes & rather no & no & & n.a. \\
\hline I know the project Digikomp8. & 204 & 62 & 22 & 84 & E & 25 \\
\hline Its requirement can be taught without an interdependent subject. & 50 & 79 & 103 & 62 & E & 92 \\
\hline An minimal standard should be obligatory. & 258 & 104 & 11 & I 4 & E & 20 \\
\hline A subject Digital Education in its own right is necessary. & 222 & 90 & 37 & 28 & E & 20 \\
\hline Content issues at Lower Secondary Level & yes & rather yes & rather no & no & & n. 2 ( \\
\hline Should all pupils learn typewriting? & 225 & 99 & 46 & I 22 & I & 6 \\
\hline The ECDL is gaining importance. & 93 & 133 & 104 & 64 & I & 4 \\
\hline I could imagine an Austrian version "ECDL light". & 134 & 112 & 58 & 82 & I & 11 \\
\hline Basics of programming should be taught obligatorily. & 72 & 115 & 127 & 76 & I & 6 \\
\hline Maker-Movement (Physical Computing, Robotics, ..) for all? & 54 & 110 & 146 & 63 & E & 22 \\
\hline Computational Thinking (Biber, ...) for all? & 110 & 160 & 73 & I 26 & E & 26 \\
\hline Suggested hours of weekly lessons of (Basic) Digital Education & zero & one & two & n.a. & & \\
\hline Grade 5 & I 26 & 211 & 113 & I 26 & & \\
\hline Grade 6 & I 22 & 208 & 119 & I 25 & & \\
\hline Grade 7 & 17 & 158 & 181 & I 22 & & \\
\hline Grade 8 & 16 & 150 & 185 & I 23 & & \\
\hline
\end{tabular}

The figures in Table 2. are speaking for themselves. There is no doubt among expert teachers that Informatics contents should have its place in primary education. Though, further investigations are necessary about the perception of the role of Informatics within Digital Education. As Fig. 2 and Digikomp4 indicate, it can be assumed that for most Austrian teachers Informatics is mainly application driven.

Another object of further research is the impact of the ECDL, respectively its syllabus, in those schools where this certificate is offered. Since 2000, the ECDL plays a substantial and successful [17] role at lower secondary level. An overwhelming majority claims an independent subject (Basic) Digital Education. This implies that there is little confidence among the respondents that the demanding objectives of Digikomp8 can be reached solely by an integrative approach. Apparently a surprise is the mixed attitude towards programming. This can be 
explained by the low confidence of teachers and by the disappearing programming activities at lower secondary level since the 90-ties.

First findings from the recent survey in December 2016, with 127 respondents and a presumably less representativeness of the sample, are outlined here.

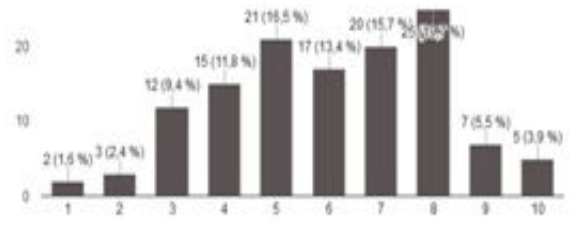

I find the situation of Digital Education...

1 - verygood .... 10 very bad (see Fig. 3)

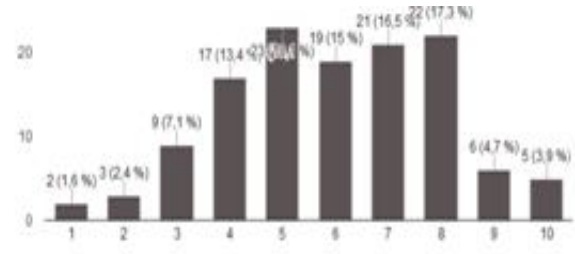

To my mind the situation of TEL in Austrian schools (technologyenhanced learning) is ...

Fig. 4. Rating of the overall situation of digital education in Austria 2016 compared to the situation of digital technology in education $(n=127)$

Compared to the rating of 2015, the survey in 2016 yields a slight shift to a more negative attitude, coincidentally with a peak also at the scale value 8 (rather bad). The similarity of both diagrams is noticeable. It might be coincidental, but the presumption that even many Austrian expert teachers still struggle with the distinction between the new term Digital Education and digitally supported and augmented learning (TEL).

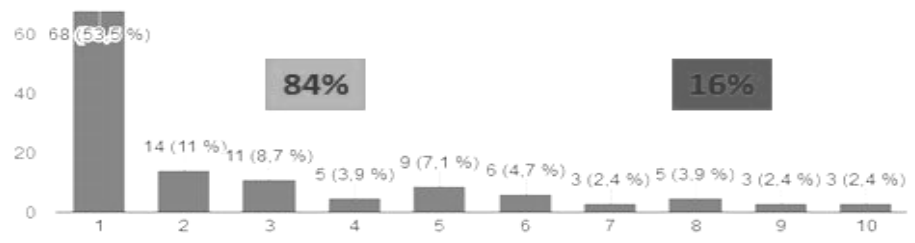

Fig. 5. Overwhelming claim for an independent subject

What is clearly evident resulting from both surveys, is the claim of a vast majority for a subject (Basic) Digital Education, in German: "Digitale Grundbildung”. "Basic" bracketed means that the denotation of the new subject was still a secret when the survey has been conducted.

\section{Towards a National Curriculum}

As indicated above, "Basic Digital Education” is the new term for a new subject with a broad curriculum. But it remains, as all the years before, an option and it is still up to the schools to implement it in an independent specific school subject. If this is not possible due to organizational or personal reasons, the integrative approach within other existing subjects is recommended, in contrast to the opinions of a vast majority of experts. 
In case of an independent subject, the amount of weekly hours will be between two and four within 120 mandatory weekly hours in four years of lower secondary education. Moreover, the subject has to be conducted as a mandatory exercise without grading. Schools can also offer mixed forms of mandatory and additional optional lessons. What is certain till now: There will be one curriculum for all four years of lower secondary education, encompassing eight main topics:

- Social Aspects of Media Change and Digitization

- Information-, Data- and Media Competence

- Operating Systems and Standard Applications

- Media Design

- Digital Communication and Social Media

- Security

- Technical Problem Solving

- Computational Thinking

Obviously these topics stand for a very broad, but seen from particular viewpoints, not necessarily balanced curriculum. Therefore it is foreseeable that this wide spectrum, starting with a clear focus on media pedagogy and digital literacy, and ending up with Informatics in the disguise of Computational Thinking, will lead to controversial, but nonetheless fruitful, discussions among teachers and experts. Besides the content areas and its requirements expressed in detailed operationalised competences [20], there will be expectedly and hopefully also discussions about the accompanying legal conditions and constraints.

\section{Concluding Remarks}

In order to assure that all pupils will be demonstrably affected by the curriculum and its intended competences at the end of lower secondary education, there will be a quality assurance measure in form of an assessment, currently denoted as Digicheck8, representing quasi educational standards for the integrative or independent subject “Basic Digital Education”.

It can be pointed out that the future national curriculum for this subject and the statutorily supported and intended change from too much arbitrariness to consolidation and accountability is basically desirable. With the measures indicated above, a first abstract and conceptual step in Austria is done, but the big challenges for a successful and concrete implementation lie ahead.

These challenges will consist of (still) conceptual, institutional, organizational and personal nature at many levels. In the view of digitally affine experts, this top down initiative was overdue and long-awaited. But nobody knows how the last but most important chain link, the schools, will react and cope with this new situation.

"That is the curse of our noble house: Striving hesitatingly on half ways to half action with half means. Yes or no, here is no middle road”. This is a quote from the stage play "A Fratricidal Struggle in the House of Habsburgers”, written by the wellknown national Austrian poet Grillparzer who lived in the $19^{\text {th }}$ century. Hopefully, this curse will be broken in the near future. 


\section{References}

1. Seehorn, D., Carey, S., Fuschetto, B., Lee, I., Moix, D., O'Grady-Cunniff, D., Boucher Owens, B., Stephenson, C., and Verno, A.: CSTA K--12 Computer Science Standards: Revised 2011. Technical Report. ACM, New York, NY, USA, (2011).

2. Curriculum England: https://www.gov.uk/government/publications/national-curriculumin-england-computing-programmes-of-study/national-curriculum-in-england-computingprogrammes-of-study\#contents, last accessed 2017/02/15.

3. Schweizer Lehrplan: http://www.lehrplan21.ch, last accessed 2017/02/15.

4. Tucker, A.: A model curriculum for k-12 computer science: Final report of the acm k-12 task force curriculum committee. Technical report, New York,NY, USA, (2003).

5. Berry, M.: Computing in the national curriculum - A guide for primary teachers. Computing at School, (2013).

6. Australian Curriculum: http://www.australiancurriculum.edu.au/technologies/introduction

7. Balanskat, A., and Engelhardt, K.: Computing our future. Computer programming and coding. priorities, school curricula and initiatives across Europe (2015). http://fcl.eun.org/documents/10180/14689/Computing+our+futurefinal.pdf/746e36b1e1a6-4bf1-8105-ea27c0d2bbe0, last accessed 2017/02/15.

8. CSTA: http://www.csteachers.org/?page=CSTA_Standards, last accessed 2017/02/15.

9. Ferrari, A.: DIGCOMP: A Framework for Developing and Understanding Digital Competence in Europe, Joint Research Centre of the European Commission, (2013).

10. Vuorikari, R., Punie, Y., Carretero Gomez S., Van den Brande, G.: DigComp 2.0: The Digital Competence Framework for Citizens. Update Phase 1: The Conceptual Reference Model. Luxembourg Publication Office of the European Union, (2016).

11. Sysło M.M., Kwiatkowska A.B.: Introducing a New Computer Science Curriculum for All School Levels in Poland. In: Brodnik A., Vahrenhold J. (Eds.) Informatics in Schools. Curricula, Competences, and Competitions. Lecture Notes in Computer Science, Vol 9378. Springer, Cham, (2015).

12. K-12 Computer Science Framework. Retrieved from http://www.k12cs.org, (2016).

13. University Klagenfurt: http://iid.aau.at/bin/view/Main/Projects, last accessed 2017/02/15.

14. Micheuz P.: A Competence-Oriented Approach to Basic Informatics Education in Austria. In: I. Kalas, R. Mittermeir (Eds.): ISSEP 2011, LNCS 7013, pp. 43-55, 2011. Springer-Verlag. Berlin Heidelberg (2011).

15. Micheuz P.: The Role of ICT and Informatics in Austria's Academic Secondary Schools. In: R. Mittermeir (Ed.): ISSEP 2005. LNCS 3422, pp. 166-177, 2006. Springer-Verlag, Berlin Heidelberg (2005).

16. eEducation Project: http://www.eeducation.at, last accessed 2017/02/15.

17. Karner E., Prumetz C.: 15 Jahre ECDL an Schulen in Österreich. In: Digitale Schule Österreich. OCG Schriftenreihe Wien (2013).

18. Narosy T.: Kein Kind ohne digitale Kompetenzen. In: Digitale Schule Österreich. OCG Schriftenreihe, Wien (2013).

19. Mulley U., Zuliani B.: Digitales Kompetenzmodell für die Volksschule. In: Digitale Schule Österreich. OCG Schriftenreihe, Wien (2013).

20. Curriculum: http://www.digitale-bildung.at/sekundarstufe-i, last accessed 2017/02/15 